\title{
Findings Related to C-Section Rates: Using Cesarean Indication Classification System
}

\author{
Seema Tanvir', Manju Chhugani' ${ }^{2}$, Merlin Mary James ${ }^{3}$
}

${ }^{1}$ M.Sc. Nursing (Obstetrics and Gynaecological Nursing) Student, ${ }^{3}$ Tutor, Rufaida College of Nursing, Jamia Hamdard, New Delhi. ${ }^{2}$ Dean, School of Nursing Sciences and Allied Health, Jamia Hamdard.

DOI: https://doi.org/10.24321/2455.9318.201820

\begin{tabular}{|c|}
\hline Abstract \\
\hline 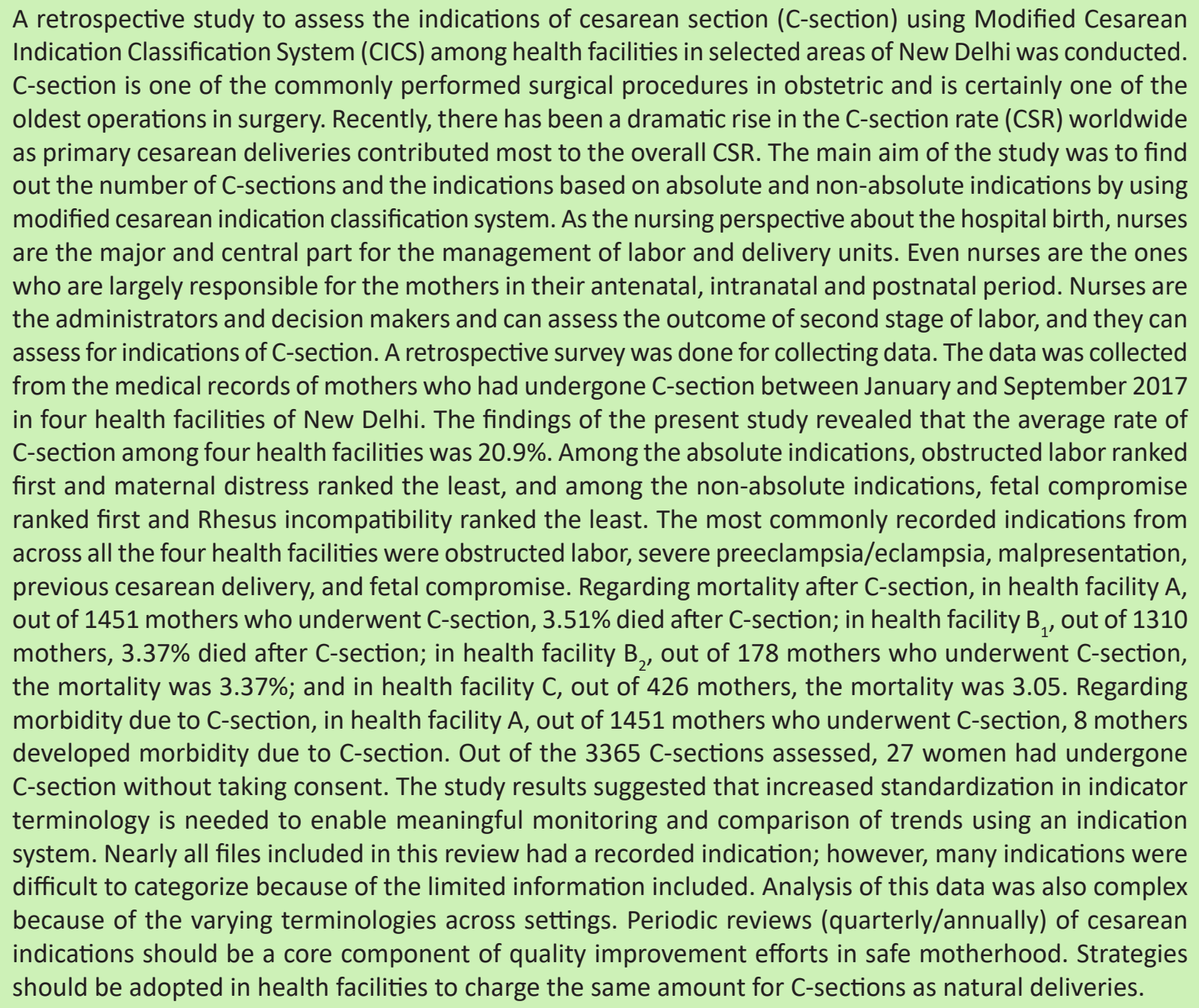 \\
\hline
\end{tabular}

Corresponding Author: Ms. Seema Tanvir, Rufaida College of Nursing, Jamia Hamdard, New Delhi.

E-mail Id: seema.hamdarduni@gmail.com

Orcid Id: https://orcid.org/0000-0002-8148-3045

How to cite this article: Tanvir S, Chhugani M, James MM. Findings Related to C-Section Rates: Using Cesarean Indication Classification System. Int J Nurs Midwif Res 2018; 5(2): 38-42. 


\section{Introduction}

Being a mother is indeed an enthralling experience in every woman's life. Pregnancy and child birth sculpts a woman into a more responsible, caring and loving individual. Each pregnant woman anticipates for the outcome of pregnancy. Her outcome of pregnancy determines her extent of satisfaction of being a mother. There are two modes of childbirth - one can be vaginal and the other cesarean. The mode of delivery cannot be fixed for each woman. It may vary from one woman to another.

The availability of cesarean section (C-section) services is one of the signal functions of comprehensive emergency obstetrics and neonatal care. The surgery is needed in many cases of obstetrics and/or fetal complications in order to save the lives of the mother, the child or at times both members of the dyad. A reassessment of evidence in 2014 prompted the WHO to state in its 2015 statement on C-section rate (CSR) that "at a population level, C-section rates higher than $10 \%$ are not associated with reductions in maternal and newborn mortality rates; C-section should ideally only be undertaken when medically necessary." ${ }^{1}$

Among the countries for which data is available, Brazil is among the highest on this parameter with a C-section rate of $56 \%$, as per data presented at the consultation. These escalating trends are being increasingly seen in some states of India as well. The latest NFHS-4 (2015-16) CSR data released for 17 states has rates several times higher than the population levels recommended by WHO. Out of the first 17 states, 11 have CSRs of over 20\%, with Telangana having the highest total CSR at $58 \%{ }^{2}$

Data from survey sources like NFHS-4 revealed that overall, private sector conducted more C-sections as a proportion of total deliveries when compared to the public health sector, with private sector CSRs often being double or several times more than the value of public sector CSRs. The states with the highest private sector CSRs among the first 17 NFHS-4 states were West Bengal and Telangana, which have private sector CSRs of $71 \%$ and $75 \%$, respectively, compared to their public sector CSRs of $19 \%$ and $41 \%$; total CSRs for these states are $24 \%$ and $58 \%$, respectively. ${ }^{2}$

In order to compare, monitor and analyze CSR within and between facilities and/or regions, it is also important to classify cases based on obstetrics risk. WHO, after reviewing many such classification systems, proposes that countries use the Robson's criteria to classify all delivery and C-section cases into 10 mutually exclusive categories that signify variable risk of complications that may necessitate a $\mathrm{C}$-section. Facilities should start using this classification as part of their case sheet records. Hence, the researcher felt the need to assess the indications of $\mathrm{C}$-section among health facilities in selected areas of New Delhi by using another system for classification, which is being developed by FIGO, i.e., Cesarean Indications Classification System, which is being further modified by the researcher.

\section{Objectives of the Study}

- To find out the number of C-sections in the selected hospitals

- To assess the indications of C-section using Modified Cesarean Indication Classification System (CICS) in the selected hospitals of New Delhi

- To find out whether the consent was taken for C-section from the client

\section{Materials and Methods}

For the present study, the quantitative research approach was considered to be most appropriate to accomplish the objectives. Since the present study was aimed to find out the rate of $\mathrm{C}$-section and indications of $\mathrm{C}$-section in selected health facilities, the research design selected was retrospective research design. The population included mothers who had undergone C-Section. The sample for the present study included mothers who underwent $\mathrm{C}$-section in the selected health facility of New Delhi from January to September 2017. Sampling technique used was total enumerative sampling technique. Reliability of the toolstructured observation checklist was checked by inter-rater reliability. The inter-rater reliability was checked and was observed by two observers. The value was computed and the reliability score was found to be $r=0.84$ which is highly reliable.

\section{Results}

The total number of deliveries was assessed in the four health facilities between January and September 2017, out of which the frequency and percentage distribution of vaginal delivery and C-sections were computed in Table 1. 
Table 1.Frequency and Percentage Distribution of Vaginal Deliveries and C-Sections in Four Health Facilities between January and September 2017

\begin{tabular}{|c|c|c|c|c|c|}
\hline Health Facility & \multicolumn{2}{|c|}{ Vaginal Delivery } & \multicolumn{2}{c|}{ C-Section } & Total \\
\hline & Frequency & Percentage (\%) & Frequency & Percentage (\%) & Frequency \\
\hline $\mathrm{A}^{*}$ & 5913 & 80.3 & 1451 & 19.7 & 7364 \\
\hline $\mathrm{B}_{1}^{* *}$ & 4698 & 78.2 & 1310 & 21.8 & 6008 \\
\hline $\mathrm{B}_{2}^{* *}$ & 1424 & 88.9 & 178 & 11.1 & 1604 \\
\hline $\mathrm{C}^{* * *}$ & 948 & 69.0 & 426 & 31.0 & 1374 \\
\hline Total & 12,983 & 79.85 & 3365 & 20.9 & 16,350 \\
\hline
\end{tabular}

${ }^{*} \mathrm{~A}-\mathrm{MCD}$ hospital, ${ }^{* *} \mathrm{~B}_{1}-$ Government hospital, ${ }^{* *} \mathrm{~B}_{2}-$ Government hospital, ${ }^{* *} \mathrm{C}-$ Private hospital

The CSRs at these four health facilities were recorded. All facilities used paper-based record-keeping systems, with multiple registers for recording service statistics. C-section indications were recorded in operating theater registers and patient records. Nearly $3365 \mathrm{C}$-section records were reviewed; nearly all (99\%) included at least one indication. Most key informants, i.e., physicians reported of being aware of various $\mathrm{C}$-section indication classification systems, but no site had a formally documented system in place. While most key informants said monthly HMIS reports were submitted on the number and type of deliveries, no site had undertaken any formal review of cesarean indications prior to this study.

\section{Findings from Patient Record File}

We found a wide range of terminology for C-section indications in the patient records. In addition to the indications listed on the data collection tool, other indications were also recorded, some of which ended up being recorded as "other, not enough information." Providers used diverse terminology for common indications.

\section{On the Basis of Indications}

In health facility A, out of 1451 C-sections, 241 women had absolute indications with a mean of 40.16 and 1210 , had non-absolute indications with a mean of 86.5. In health facility $B_{1}$, out of 1310 C-sections, 314 women had absolute indications with a mean of 52.33 and 996 had non-absolute indications with a mean of 71.14. While in health facility $B_{2}$ out of $178 \mathrm{C}$-sections, 31 women had absolute indications with a mean of 5.17 and 147 had non-absolute indications with a mean of 10.5. And in health facility C, out of 426 C-sections, 105 women had absolute indications with a mean of 17.5 , and 321 had non-absolute indications with a mean of 22.93 .

Overall, out of 3365 C-sections, 691 (20.53\%) mothers had absolute indications and 2674 (79.47\%) mothers had non-absolute indications.

Table 2.Frequency, Percentage Distribution and Rank Order of Absolute Indications of C-Section in Four Health Facilities

\begin{tabular}{|c|c|c|c|c|c|c|c|}
\hline & & & & & & \multicolumn{2}{|c|}{$N\left(n_{1}+n_{2}+n_{3}+n_{4}\right)=3365$} \\
\hline \multirow[t]{2}{*}{$\begin{array}{l}\text { S. } \\
\text { No. }\end{array}$} & Indications & $\begin{array}{c}\text { Health } \\
\text { Facility A }\end{array}$ & $\begin{array}{l}\text { Health } \\
\text { Facility } \\
\mathrm{B}_{1}\end{array}$ & $\begin{array}{l}\text { Health } \\
\text { Facility } \\
\mathrm{B}_{2}\end{array}$ & $\begin{array}{l}\text { Health } \\
\text { Facility } \\
\text { C }\end{array}$ & Total & $\begin{array}{l}\text { Rank } \\
\text { Order }\end{array}$ \\
\hline & & Frequency & Frequency & Frequency & Frequency & Frequency & \\
\hline $5 a$ & Absolute Indications & & & & & & \\
\hline $5 a .1$ & $\begin{array}{l}\text { Obstructed labor (CPD and } \\
\text { failed trial of labor) }\end{array}$ & 120 & 113 & 14 & 29 & 276 & 1 \\
\hline $5 a .2$ & Uterine rupture & 4 & 26 & 0 & 12 & 42 & V \\
\hline $5 a .3$ & $\begin{array}{l}\text { Malpresentation (including } \\
\text { transverse, oblique and brow) }\end{array}$ & 65 & 117 & 10 & 47 & 239 & II \\
\hline $5 a .4$ & $\begin{array}{c}\text { Major antepartum } \\
\text { hemorrhage and grade } 3 \text { or } 4 \\
\text { placenta previa }\end{array}$ & 13 & 14 & 2 & 7 & 36 & IV \\
\hline $5 a .5$ & Unfavorable cervix & 26 & 17 & 3 & 5 & 51 & III \\
\hline $5 a .6$ & Maternal distress & 13 & 27 & 2 & 5 & 47 & $\mathrm{VI}$ \\
\hline
\end{tabular}


Table 3.Frequency, Percentage Distribution and Rank Order of Non-Absolute Indications of C-Section in Four health facilities

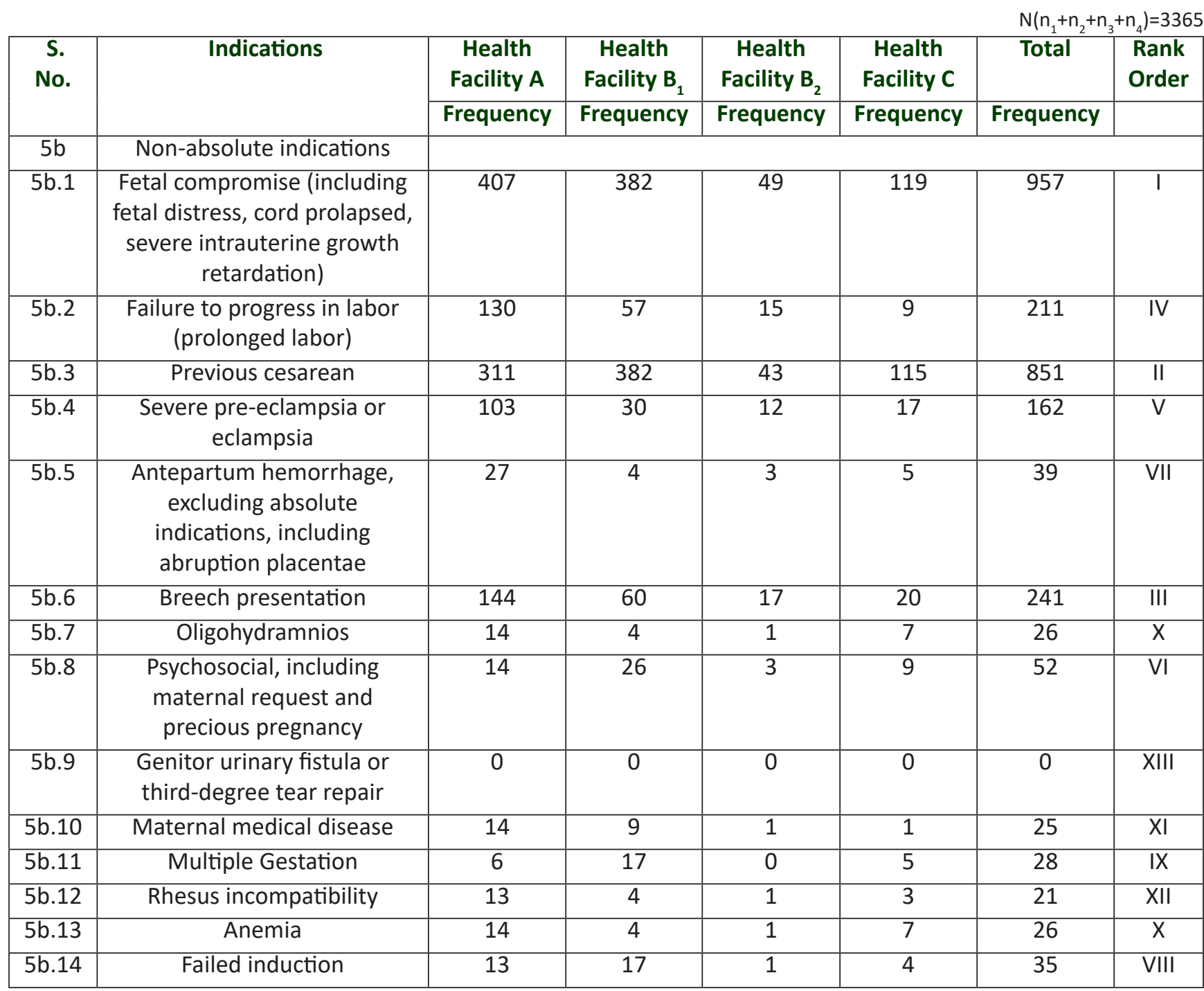

The data presented in Tables 2 and 3 shows that among absolute indications, obstructed labor ranked one and maternal distress ranked the least, and among non-absolute indications, fetal compromise ranked number one and Rhesus incompatibility ranked the least.

\section{Consent}

In all four health facilities, out of 3365 C-sections, consents were not taken from 27 mothers.

\section{Discussion}

The 2008 CSRs at these facilities ranged from 7\% (at Niger C) to $53 \%$ (in Bangladesh). For comparison, estimated national cesarean rates for similar time periods were $2 \%$ or less in Guinea, Mali, and Niger; $5 \%$ in Uganda; and 17\% in Bangaladesh. C-section indications were recorded in operating theater registers and patient records. A total of 2941 C-section records were reviewed; nearly all (99\%) included at least one indication. The findings are supported by the present study in which the rates of $\mathrm{C}$-section at health facilities were $20.53 \%$ and each C-section case was categorized into absolute (20.53\%) and non-absolute $(79.47 \%){ }^{4}$

In the present study, the findings showed that the commonest absolute indication was obstructed labor (39.94\%), in non-absolute indications fetal compromise ranked first (35.77\%) and previous CS ranked II (31.81\%). These findings are similar to the study done by Singh and Gupta, in which the commonest recorded indications for CS were: previous CS (29.4\%), fetal distress (15.7\%), cephalopelvic disproportion (10.2\%), prolonged obstructed labor (8.3\%) and post-term dates (7.0\%).

According to NFHS-4, Telangana state has the dubious distinction of having the highest CSR in the country. Close to $58 \%$ of pregnant women undergo $\mathrm{C}$-section in Telangana followed by Andhra Pradesh, which is at $40 \%$. According to 
NFHS survey in northern states such as Haryana, Madhya Pradesh, Uttarakhand and Bihar, the CSR has hovered anywhere from $21 \%$ to as low as $13 \%$. This is not just an Indian trend, even worldwide, C-section is becoming a major public health concern due to potential risks to mothers, infants and costs. Overall, when compared to other countries India has an average CSR of 20 while Brazil has the highest at 55.6. The divide between private and public health institutions too is quite visible. In Telangana, CSR in private hospitals is 75 for 100 live births while in public health institutions it is 40.6. ${ }^{3}$ The study findings are similar to the present study findings in which CSR in four health facilities was $20.9 \%$.

\section{Conclusion}

The total number of deliveries in all the four health facilities was 16,350 between January and September 2017, out of which $79.85 \%$ were vaginal deliveries and $20.9 \%$ C-sections. In absolute indications, obstructed labor ranked number one and maternal distress ranked the least and in nonabsolute indications, fetal compromise ranked number one and Rhesus incompatibility ranked the least. Out of 3365 C-sections, consent was not taken from 27 mothers, in health facilities. The findings of the study have implications for nursing practice, nursing education, nursing administration and nursing research. The CSR is alarmingly increasing in India; the number has doubled in the past decade. At the institution level, low CSRs are often the best indicator of quality. Hence, nurses should be educated about identifying the absolute and non-absolute indications of C-section. Nurses should educate women about benefits of natural deliveries. For education in nursing, student nurses may be provided with learning experiences related to identification of indications for C-section and further educate them about documentation of the findings using an observation checklist to assess the indications. The findings of the study have implications for administration for continuing/ in-service education programs for the nurses: short-term courses can be organized to update them with knowledge on identification of indications for $\mathrm{C}$-section and keep them abreast with the knowledge on newer classification system for $\mathrm{C}$-section. Further studies can be done at many health facilities to generalize the findings and to find the best practices. Patient record keeping should be strengthened as it is an important component of processes for quality improvement and HMIS strengthening in settings. Periodic reviews (quarterly/annually) of cesarean indications should be a core component of quality improvement efforts in safe motherhood. Strategies should be adopted in health facilities to charge the same amount for C-sections and natural deliveries. Further, retrospective studies can be done to compare the CSRs in private and public health facilities. Research studies can be done to assess the opinion of women who have undergone C-section in terms of preference, complications, and maternal-infant bonding. Prospective studies can be done to assess the long-term complications of C-sections.

\section{Conflict of Interest: None}

\section{References}

1. World Health Organization. Appropriate technology for birth. Lancet 1985; 2(8452): 436-37.

2. Radhakrishnan T, Vasanthakumari KP, Babu PK. The increasing trend in caesarean section rates: Global, regional and national estimates: 1990-2014. PLOS ONE 2016; 11(2): e0148343.

3. Veenakumara K. Vidhana Parishad, Telangana. Times of India.

4. https://fistulacare.org/wp-fcp/wp-content/ uploads/2016/11/Findings_From_Five_Countries_ Cesarean_Indication_Brief-11-9-16.pdf.

5. Singh G, Gupta ED. Rising incidence of caesarean section in rural area in Haryana India: A retrospective analysis. The Internet Journal of Gynecology and Obstetrics 2013; 17(2).

Date of Submission: 2018-05-23 Date of Acceptance: 2018-06-14 